\title{
Perbandingan Antara Kekuatan Bahu dan Kekuatan Tungkai Pemain Bola Voli dan Bola Basket Mahasiswa IKIP PGRI Pontianak
}

\author{
${ }^{1}$ Asmutiar, ${ }^{2}$ Mohammad Sabransyah \\ 1,2IKIP PGRI Pontianak, Pontianak, Kalimantan Barat, Indonesia \\ 1asmu_tiar@yahoo.com, 2sabran.pjkr@gmsil.com
}

\begin{abstract}
ABSTRAK
Permianan bola basket dan bola voli memiliki pola gerak dan penggunaan bagian tubuh yang hampir sama dari kedua teknik. Tetapi belum diketahui kekuatan bahu dan kekuatan tungkai mana dari kedua cabang olahraga tersebut yang memiliki kekuatan tinggi untuk melakukan teknik lompatan, smass dan shooting. Penelitian ini untuk mengetahui ada atau tidak perbandingan kekuatan bahu dan tungkai pemain bola basket dan bola voli. Kausal Komparatif (causal comparative research). Hasil tes push and pull Dynamometer pemain basket dan voli, Nilai t hitung adalah -0.187 bulatkan nilai tersebut dan bandingkan dengan $t$ tabel. Nilai t hitung $(0.187)<t^{\text {tabel }} 0,05 ; 14=1.76131$ sehingga Ho diterima. Hasil tes Back and Leg Dynamometer pemain basket dan voli, Nilai t hitung adalah -0.604 bulatkan nilai tersebut dan bandingkan dengan $t$ tabel. Nilai $t$ hitung $(0.604)<t$ tabel 0,$05 ; 14=1.76131$ sehingga Ho diterima. Dengan demikian hipotesis yang menyatakan apakah ada perbandingan antara kekuatan bahu dan kekuatan tungkai pemain bola basket dan pemain bola voli mahasiswa IKIP PGRI Pontianak, tidak diterima kebenarannya.
\end{abstract}

Kata Kunci: Bola Basket, Bola Voli, Kekuatan Bahu, Kekuatan Tungkai

\section{ABSTRAC}

The game of basketball and volleyball has a pattern of motion and use of almost the same body parts from both techniques. But it is not yet known which shoulder strength and leg strength of the two sports branches have high strength to do the jumping, smass and shooting techniques. This research is to find out whether or not there is a comparison of the shoulder and limb strength of basketball and volleyball players. Causal Comparative (causal comparative research). Push and pull test results for basketball and volleyball players, the calculated $t$ value is -0.187 round the value and compare it with the $t$ table. $T$ value $(0.187)<t$ table 0.05 ; $14=1.76131$ so that Ho is accepted. Back and Leg Dynamometer test results for basketball and volleyball players, the calculated $t$ value is -0.604 round that value and compare it to the $t$ table. $T$ value $(0.604)<t$ table $0.05 ; 14=1.76131$ so that Ho is accepted. Thus the hypothesis which states whether there is a comparison between shoulder strength and leg strength of basketball players and volleyball players of IKIP PGRI Pontianak students, is not accepted.

Keyword: Basketball, Volleyball, Shoulder Strength and Leg Strength

Alamat Korespondensi: IKIP PGRI Pontianak

Email: asmu tiar@yahoo.com

(C) 2020 STKIP Pasundan

ISSN 2721-5660 (Cetak) 


\section{PENDAHULUAN}

Perkembangan yang cukup pesat ditunjukkan untuk setiap cabang olahraga di Indonesia, ini dapat dilihat dari banyaknya pertandingan yang diselengarakan baik tingkat pelajar, mahasiswa dan masyarakat umum. Perencanaan yang matang diperlukan untuk membangun sebuah tim, dimana tim tersebut memiliki kemampuan teknik, taktik, strategi dan kondisi fisik yang baik demi mencapai prestasi tertinggi. Karena beberapa faktor yang mempengaruhi prestasi antara lain adalah kemampuan teknik, konsentrasi dan kondisi fisik (Landers et al., 2013). Perencanaan yang dimaksud adalah latihan yang cukup lama kepada setiap pemain atau atlit untuk memiliki teknik, taktik, serta dapat memahami strategi yang diberikan oleh pelatih dan ada peningkatan terhadap kondisi fisik mereka.

Latihan merupakan syarat mutlak dalam meningkatkan suatu keterampilan teknik dan kondisi fisik sampai menuju puncak prestasi. Latihan adalah salah satu faktor pendukung dalam rangka mencapai puncak keberhasilan seorang atlet. Atlet yang dapat mencapai puncak prestasi itu merupakan hasil dari suatu program yang terbentuk dari berbagai unsur yang diintegrasikan menjadi suatu pedoman latihan bagi atlet, sehingga hasil dari latihan tersebut bisa dipertanggungjawabkan. Kemajuan dan kemunduran prestasi atlet juga tergantung dari program latihan, dengan demikian pelatih harus mampu dan jeli akan kebutuhan atau kekurangan yang harus ditingkatkan dari atlet. Salah satu cara melihat kemajuan seorang atlet adalah dengan mengevaluasi secara objektif, transparan dan menyeluruh.

Usaha pencapaian puncak prestasi atlet tidaklah mudah, perlu suatu ketajaman pengetahuan dalam penyusunan program latihan, disamping itu pelatih harus mampu menguasai atlet secara psikologis sehingga atlet merasa nyaman dan termotivasi dalam berlatih. Proses perencanaan suatu program latihan haruslah mengacu kepada prosedur yang terorganisasi dengan baik (well organized), yang metodis, dan yang ilmiah, agar dengan demikian program tersebut bisa membantu atlet untuk mencapai prestasi yang setinggi-tingginya. Jadi perencanaan program atau training plan merupakan alat yang penting bagi pelatih untuk bisa melaksanakan program secara well organized. Tanpa kemahiran pelatih dalam menyusun suatu program latihan yang baik, maka tidak mungkin pula dia bisa melaksanakan training secara terorganisasi dengan baik.

Cabang olahraga bola voli dan bola basket menggunakan kondisi fisik yang hampir sama, diantaranya menggunakan kekuatan otot, daya tahan otot, daya tahan pernapasan kardiovaskuler, fleksibilitas dan komposisi tubuh. Berdasarkan karakter gerak antara basket dan voli menggunakan kekuatan bahu untuk melakukan gerakan smash dalam bola voli dan shooting dalam bola basket, kemudian kekuatan tungkai kaki digunakan untuk gerakan melompat saat smash pada permainan bola voli dan gerakan lay up pada permainan bola basket. Hal tersebut membuktikan bahwa gerakn yang yang dilakukan harus explosive dan cepat, ini berarti 
menandakan dalam setiap cabang olahraga memang faktor kekuatan dan power sangat dibutuhkan. Kemampuan biomotor seperti explosive power dan kecepatan merupakan komponen penting yang diperlukan pada setiap cabang olahraga (Perikles, E. Y., Mintarto, E., \& Hasan, N, 2016). Kemampuan fisik yang prima bagi atlet merupakan suatu hal yang penting agar dapat melaksanakan proses latihan secara optimal, dan hanya atlet yang berlatih secara optimal yang berpotensi untuk meraih prestasi yang optimal (Harsuki, 2003).

Secara garis besar permainan Bola basket dilakukan dengan mempergunakan tiga unsur teknik yang menjadi pokok permainan, yakni : mengoper dan menangkap bola (pasing and catching), menggiring bola (dribbling), serta menembak (shooting), teknik latihan olah kaki (footwork) (Ahmadi, 2007 : 13). Permainan bola voli adalah bentuk permainan beregu yang mengandalkan keterampilan setiap pemain, maka dalam permainan ini memerlukan penguasaan teknik dasar sebaik mungkin agar dapat bermain dengan baik, maka perlulah kiranya setiap pemain secara perorangan berusaha meningkatkan penguasaan teknik dasar dalam permainan bola voli secara sempurna (Suharno, $1993: 12$ ).

Berdasarkan pemaparan diatas, dapat dilihat bahwa ada pola gerak dan penggunaan bagian tubuh yang sama dari kedua teknik diatas. Tetapi belum diketahui kekuatan bahu dan kekuatan tungkai mana dari kedua cabang olahraga tersebut yang memiliki kekuatan tinggi untuk melakukan teknik lompatan, smass dan shooting. Oleh sebab itu, kami ingin melakukan penelitian tentang masalah "Perbandingan Antara Kekuatan Bahu Dan Kekuatan Tungkai Pemain Bola Voli Dan Bola Basket Mahasiswa Ikip Pgri Pontianak".

\section{METODE}

Penelitian ini menggunakan metode Kausal Komparatif (causal comparative research). Penelitian kausal komparatif disebut juga penelitian ex post facto adalah penyelidikan empiris yang sistematis di mana ilmuwan tidak mengendalikan variable bebas secara langsung karena eksistensi dari variable tersebut pada dasarnya tidak dapat dimanipulasi (Emzir, 2012 : 119). Menurut Aswarni Sudjud (dalam Suharsimi Arikunto, 2006 : 267), mengatakan bahwa: "Penelitian Komparatif (perbandingan) akan dapat menemukan persamaan dan perbedaan tentang benda-benda, tentang orang, tentang prosedur kerja, tentang ide-ide, krirtik terhadap orang, kelompok, terhadap suatu ide atau suatu prosedur kerja.

Desain penelitian kausal komparatif menurut Gay (dalam Emzir, 2012 : 127), adalah sangat sederhana, dan walaupun variabel bebas tidak dimanipulasi, ada prosedur kontrol yang dapat diterapkan. Dalam penelitian ini tidak ada perlakuan, langsung pengambilan posttest (tes akhir). Desain dasar penelitian kausal komparatif (Gay dalam Emzir, 2012 : 127) sebagai berikut: 
Tabel 1. Desain Penelitian

\begin{tabular}{|c|c|c|c|}
\hline Kasus & Kelompok & Variabel Bebas & Variabel Terikat \\
\hline $\mathrm{B}$ & $(\mathrm{E})$ & $\left(\mathrm{X}_{1}\right)$ & 0 \\
\hline & $(\mathrm{K})$ & $\left(\mathrm{X}_{2}\right)$ & 0 \\
\hline
\end{tabular}

Emzir (2012 : 128) menjelaskan bahwa Desain dasar penelitian kausal komparatif melibatkan pemilihan dua kelompok yang berbeda pada beberapa variabel bebas dan membandingkan mereka pada beberapa variabel terikat. Hasil analisis dinyatakan terdapat perbedaan jika nilai signifikansi kurang dari 0,05 $(\mathrm{P}<0,05)$. Populasi dalam penelitian ini adalah seluruh pemain bola basket berjumlah 15 mahasiswa dan bola voli 15 mahasiswa yang tergabung dalam UKM Basket dan Voli. Mengukur kekuatan dan daya tahan otot lengan dan otot bahu yaitu dengan alat tes push and pull Dynamometer. Mengukur kekuatan tungkai adalah dengan menggunakan Back and Leg Dynamometer.

\section{HASIL DAN PEMBAHASAN}

Uraian deskripsi data hasil penelitian ini bertujuan untuk melihat secara umum gambaran hasil skor dari kekuatan pada masing-masing tes adalah sebagai berikut:

Tabel 2. Rekapitulasi Deskripsi Data Push Dynamometer dan Leg Dynamometer

\begin{tabular}{|c|c|c|c|}
\hline \multicolumn{4}{|c|}{ Push Dynamometer } \\
\hline Kelompok & $\mathbf{N}$ & Rerata & Rerata Delta \\
\hline Bola Basket & 15 & 33.13 & \multirow{2}{*}{0,53} \\
\hline Bola Voli & 15 & 33.67 & \\
\hline \multicolumn{4}{|c|}{ Leg Dynamometer } \\
\hline Kelompok & $\mathbf{N}$ & Rerata & Rerata Delta \\
\hline Bola Basket & 15 & 69.53 & \multirow{2}{*}{2} \\
\hline Bola Voli & 15 & 71.53 & \\
\hline
\end{tabular}

Tabel 3. Hasil Uji Beda Kemampuan Push Dynamometer Kelompok Basket dan Voli

\begin{tabular}{|c|c|c|c|}
\hline Variabel & $\mathbf{t}_{\text {hitung }}$ & Signifikansi (p) & Status \\
\hline Kekuatan Bahu &,- 187 &, 854 & Tidak ada Perbandingan \\
\hline
\end{tabular}

Nilai thitung adalah -0.187 bulatkan nilai tersebut dan bandingkan dengan $\mathrm{t}$ tabel. Nilai $\mathrm{t}$ hitung (0.187) < tabel ${ }_{0,05 ; 14}=1.76131$ sehingga Ho diterima. Hasil perhitungan dari tabel diatas bisa di buat kesimpulan bahwa $t_{\text {hitung }}$ lebih kecil dari $t_{\text {tabel }}$ dan nilai probabilitas diatas 0,05 , maka hipotesis nol diterima yang berarti tidak terdapat perbedaan rerata skor push dynamometer pemain bola basket dan pemain voli. Disimpulkan bahwa tidak terdapat perbandingan antara kekuatan bahu pemain bola basket dan pemain bola voli mahasiswa IKIP PGRI Pontianak.

Tabel 4. Hasil Uji Beda Kemampuan Push Dynamometer Kelompok Basket dan Voli

\begin{tabular}{|l|l|l|r} 
Variabel & $t_{\text {hitung }}$ & Signifikansi (p) & Status \\
\hline
\end{tabular}




\begin{tabular}{|l|l|l|l|}
\hline Kekuatan Tungkai &,- 604 &, 556 & Tidak ada Perbandingan \\
\hline
\end{tabular}

Nilai thitung adalah -0.604 bulatkan nilai tersebut dan bandingkan dengan $\mathrm{t}$ tabel. Nilai $\mathrm{t}$ hitung $(0.604)<$ tabel $_{0,05 ; 14}=1.76131$ sehingga Ho diterima. Hasil perhitungan dari tabel diatas bisa di buat kesimpulan bahwa $t_{\text {hitung }}$ lebih kecil dari $t_{\text {tabel }}$ dan nilai probabilitas diatas 0,05 , maka hipotesis nol diterima yang berarti tidak terdapat perbedaan rerata skor leg dynamometer pemain bola basket dan pemain voli. Disimpulkan bahwa tidak terdapat perbandingan antara kekuatan tungkai pemain bola basket dan pemain bola voli mahasiswa IKIP PGRI Pontianak.

\section{KESIMPULAN}

Tidak terdapat perbandingan antara kekuatan bahu pemain bola basket dan pemain bola voli mahasiswa IKIP PGRI Pontianak, dengan hasil perhitungan ( $\mathrm{t}$ hitung $0.187<\mathrm{t}^{\text {tabel }} \mathrm{0}_{0,05 ; 14}=$ 1.76131). Tidak terdapat perbandingan antara kekuatan tungkai pemain bola basket dan pemain bola voli mahasiswa IKIP PGRI Pontianak, dengan hasil perhitungan thitung $(0.604)<$ tabel $_{0,05 ; 14}$ = 1.76131). Berdasarkan hasil penelitian diketahui bahwa, kekuatan bahu dan kekuatan tungkai pemain bola basket dan pemain bola voli IKIP PGRI Pontianak tidak memiliki perbandingan atau perbedaan yang signifikan setelah dilakukan uji secara statistik. Ini bisa terjadi jika bentuk latihan atau program latihan kedua cabang ini hampir sama dalam intensitas, durasi, dan repetisi.

\section{SARAN}

Sehubungan dengan simpulan yang telah diambil dan implikasi kata yang ditimbulkan, maka disarankan bahwa Ada kecendrungan kemampuan bahu dan kemampuan tungkai pada mahasiswa IKIP PGRI Pontianak sama atau memiliki perbedaan yang sangat kecil yang disebabkan latihan dengan intensitas sama. Untuk meningkatkan kekuatan bahu dan kekuatan tungkai diperlukan latihan khusus terhadap kedua varibel tersebut.

\section{DAFTAR PUSTAKA}

Ahmadi, Nuril. 2007. Permainan Bolabasket. Surakarta: Era Intermedia

Arikunto, 2006. Prosedur Penelitian, Suatu Pendekatan Praktik. Jakarta. PT Rineka Cipta.

Emzir, 2012. Metodologi Penelitian Pendidikan, Kuantitatif dan Kualitatif. Jakarta. Rajawali Pers. Harsuki. (2003). Perkembangan Olahraga Terkini. Jakarta : Rajawali Sport, Rajagrafindo Persada Landers, D. M., Boutcher, S. H., Wang, M. Q., Landers, D. M., Boutcher, S. H., \& Wang, M. I. N. Q. (2013). A Psychobiological Study of Archery Performance A Psychobiological Study of Archery Performance. Research Quarterly for Exercise and Sport, (March 2015), 37-41. https://doi.org/10.1080/02701367.1986.10605403 
Perikles, E. Y., Mintarto, E., \& Hasan, N. (2016). Pengaruh Latihan Jump To Box , Front Box Jump , dan Depth Jump Terhadap Peningkatan Explosive Power Otot Tungkai dan Kecepatan. Media Ilmu Keolahragaan Indonesia, 6(1), 8-14. Retrieved from. Rasyono. FIK Universitas Jambi. Journal of Physical Education, Health and Sport.2016.vol 1. P1

Suharno, H.P. 1993. Ilmu Coaching Umum. Yogyakarta. Direktorat Keolahragaan Ditjen Diklusepora. 